\title{
A Modern Strategy for the Development of Academic Staff Based on University-Industry Knowledge Transfer Effectiveness \& Collaborative Research
}

\author{
Saima Iqbala, Abeda Muhammad Iqbala*, Adnan Shahid Khan ${ }^{b}$, Aslan Amat Senina \\ ${ }^{a}$ Faculty of Management and Human Resource Development, Universiti Teknologi Malaysia, 81310 UTM Johor Bahru, Johor, Malaysia \\ ${ }^{b}$ UTM-MIMOS Center of Excellence, Faculty of Electrical Engineering, Universiti Teknologi Malaysia, 81310 UTM Johor Bahru, Johor, Malaysia \\ *Corresponding author: abidaiqbal49@yahoo.com
}

\section{Article history}

Received :4 April 2013

Received in revised form :

25 July 2013

Accepted :15 October 2013

\begin{abstract}
University and industry has substantially contributed to enhancing the quality of life. As a result, transdisciplinary scientific communities have come to play a vital role to produce new knowledge with effective applications for rapid technological change and innovation to be a competitive globally. For this purpose study provide a framework for the development of academic staff of higher education. We used University-Industry collaboration as the channel to develop and encourage teachers, doctors, professors and researchers with the help of research relationship. The paper contributes to the literature on university-industry interactions to improve applied knowledge, skills and practices of academic staff and enhancement on technology innovation and commercialization. Secondly, our aim to provide an efficient mechanism of knowledge transfer effectiveness (KTE) and collaborative research (CR) those are available to transfer and share knowledge and information from university to industry effectively and to eliminate major obstacles of knowledge transfer by using productive knowledge transfer indicators (KTIs). Research findings indicates the question is, how the process of university-industry interaction will be managed at different stages for the success of knowledge transfer and how knowledge gap is reduced through effective interactions. By adopting this framework any university or industry can easily cross the threshold in the grown-up academic and research collaborational community.
\end{abstract}

Keywords: Professional development of academic staff; university-industry collaboration; knowledge transfer effectiveness; collaborative research; knowledge transfer indicators

(C) 2013 Penerbit UTM Press. All rights reserved.

\subsection{INTRODUCTION}

The success of science and technology (S\&T) policies is judged from the fact that how much it has contributed to the advancement of knowledge, which then can be harnessed in terms of new technological development. In this direction, the developing countries are experiencing post academic revolution leading to a new privatized and international or globalized mode of scientific development. As a result, trans-disciplinary scientific communities have come to play a vital role to produce new knowledge with effective applications for rapid technological change and innovation to be a competitive global (Kharbanda, 2011). Academic staffs are the heart and soul of the university, and only with a well-qualified academic staff will it be possible to have meaningful development in higher education and corporate sectors (HEC Pak, 2011). Academics work in increasingly complex institutional environments. Universities become more engaged with commercial activities at the same time that they generate new internal structures to manage research activities. Faculty members are the principal agents through whom these interactions develop and mature (Monica, 2010). Professional Development of academic staff is important to renew knowledge and skills of faculty members. It is an essential element to improve quality of education delivered to students. In general, development of an individual in his academic career and professional role (Villegas-Reimers, 2003). It is an essential element to improve quality of education delivered to students. By the use of professional development activities teachers knowledge, skills and teaching capabilities could be enhanced and the immediate beneficiaries could be students and society in general (Aslam, 2011).

In university-industry Collaboration knowledge transfer emphasize on existing personal communication, cooperative education, and personal exchanges (Abeda, 2011). Knowledge transfer exchange is a highly valuable activity and an interactive process involving the interchange of knowledge between research users (Industry and Stakeholders) and research producers (University's Researchers). There are a number of hindrances exist in exchanges of knowledge between university and industry. In this context, our attempt to eliminate major obstacles by using 